\title{
Web-based Information Models to Support Product Development in Virtual Enterprises
}

\author{
Arturo Molina, José L. Acosta, Ahmed Al-Ashaab, Karina Rodríguez \\ Concurrent Engineering Research Group, CSIM/DIA, ITESM Campus Monterrey, E. Garza \\ Sada 250, Sur. C.P. 64849, Monterrey, N.L. Mexico. armolina@_ampus.mty.itesm.mix
}

\begin{abstract}
Two information models have been defined to be key elements to support Product Development, namely: Product and Manufacturing Models. The Product Model contains all data related to a product's life cycle. The Manufacturing Model describes the capabilities and capacities of manufacturing facilities. The objective of these two information models is to assist simultaneous design teams by providing access to consistent sources of product and manufacturing information, and therefore allow computer applications to be developed to support concurrent design.

In a Virtual Enterprise, product development has to be carried out by distributed teams of different companies, therefore there is a need for these two models to be available in an environment which can be shared regardless where the teams are located. The use of Web technology has been defined to be useful to share product information and manufacturing technical capabilities among global companies. A Product and Manufacturing Models have been developed in prototype systems based on an object oriented database using Web technology to support the following application system: Design for Injection Moulding and Selection of suppliers for Product Development in a Virtual Enterprise.
\end{abstract}

Key words: Information Models, Knowledge Model, Virtual Enterprise, Web technology, Object Oriented Database. 


\section{INTRODUCTION}

Increased competition in the global market place has forced companies to look for methods and technologies, which will improve the quality of their products, reduce the product development cycle and reduce production costs. Competitive advantage is driven by three major strategies: achieve mass customisation, become low cost suppliers and create leading edge products. These strategies in a global manufacturing environment must be implemented through the use of best practices (e.g. Concurrent Engineering) and computer technologies (e.g. Web-based engineering applications). However it requires effective collaboration and efficient management of product life cycle information in order to support engineering decisionmaking happening in geographically distributed enterprises [3]. Internet technologies addresses this need by providing services to share and transfer the knowledge and information across networked enterprises. Internet-based applications are designed to allow product information to be shared between extended enterprise partners. This comprises OEM (Original Equipment Manufacturers), supply chains, subsidiaries, consultants, and partners affiliated with the product's life cycle. Key issue in this context is Product and Manufacturing information and knowledge provision. The challenge is to allow accessibility to all parties involved in the process of a product development. This paper describes how Product and Manufacturing information/knowledge can be structured and organised in information models to support global product development. Web-applications based have been developed in order to demonstrate how these information models can be used in a global collaborative environment. Case studies are presented of how these models can support Product Development in a Virtual Enterprise, specifically: Design for Injection Moulding and Selection of suppliers for Product Development.

\section{MODELLING INFORMATION AND KNOWLEDGE FOR INTEGRATED PRODUCT DEVELOPMENT}

Modelling information and knowledge for product development is key for successful engineering collaboration in a global environment. Efforts in modelling information to support product development has concentrated in [9]:

1. Modelling product information to represent the important aspects of products throughout their life cycle i.e. requirements, design, manufacturing, production, packaging, distribution and recollection. 
2. Modelling manufacturing information in order to capture the capabilities and capacities of manufacturing processes and resources of a particular facility.

The research reported here describes methodologies for modelling product and manufacturing information and knowledge.

\subsection{Modelling Product Information}

Research related to model product information has evolved in computerbased environments, which support the integration of automated applications. Details can be found in Krause et al. [6]. The Product Model should represent all the information needed throughout the life cycle of the product i.e. requirements, design, manufacture, production, assembly, packaging, distribution and recollection. The methodology developed and applied in this research has the following phases:

1. Design process analysis and documentation using IDEF0.

2. Analysis of product data and information

3. Product Model Configuration: function, solution and physical models.

4. Product Model Construction and documentation using EXPRESS

5. Product Model implementation using Object Oriented Database

The use of IDEFO model in the analysis and documentation is key to capture and formalise the company's design process. The graphical representation of the process established a common ground for discussion between the members of the engineering team in charge of the Product Model construction. Experiences with the application of IDEF0 in this task has shown that this model offers an overall picture of the process by representing the product information flow (e.g. reports, drawings, technical data), control points (e.g. checklist, formats, standards), responsibilities of engineers, and technology support (e.g. CAD, CAE, Databases). In addition, it is also useful for the identification of areas of opportunity for the improvement of the design process. Once the IDEF0 model has been constructed and approved by the SE team, the product model configuration takes place based on the product information analysed and recollected during the previous stage. Three important models have to be structured and constructed: function, solution and physical (figure 1). The description based on a function must satisfy user requirements and is expressed in those terms, in figure 1 , for example in glass bottle design (e.g. volume, weight). The solution model has two descriptions: possible solutions to satisfy the function of a product and analysis required for satisfying different aspects of 
the life cycle. For example, the bottle design requires thermal and blow analysis Finally, the physical model describes how the product is structured in assemblies, sub-assemblies, components, parts and materials. The bottle is one product but have different regions for design: crown, neck, elbows, body and bottom. Relationships between all these elements must have a parametric definition e.g. how geometric variables related to each other angles and radius. In order to comply with industry standards all information have to be documented using EXPRESS, in addition wherever possible STEP definitions have been used to represent geometric, material, tolerance and topology data. An EXPRESS model can easily be mapped into the Object Oriented Database language due to the flexibility of the language to represent all the information types defined by EXPRESS i.e. entities, lists, bags, arrays, etc.

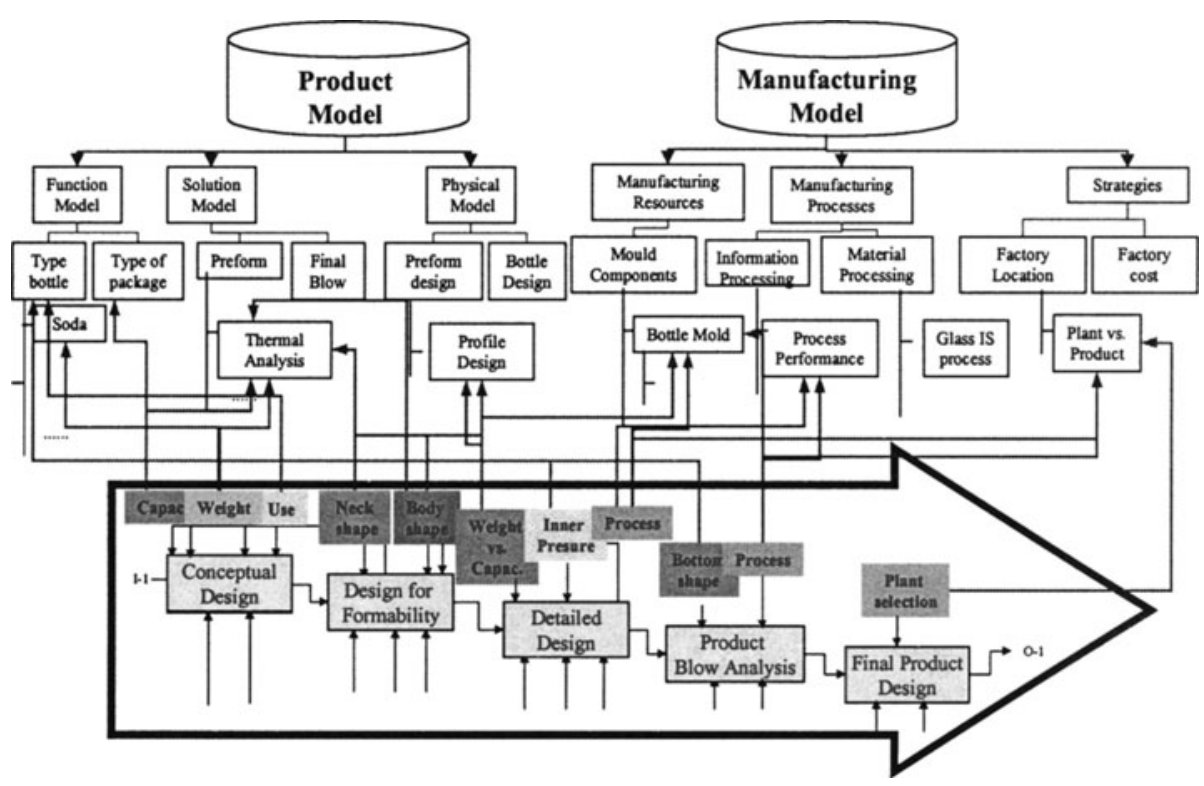

Figure 1. Structure and relationships of Product and Manufacturing Models.

\subsection{Modelling Manufacturing Information}

The rapid development of computer-aided information technologies has triggered the development of a second type of models, which complements 
the information required to achieve concurrent design. These information models represent factories i.e. machine tools, tools, manufacturing processes, material flow, orders, etc. The basis for the research into this type of data models came from original work done by the ESPRIT Project IMPPACT on a Factory Model [5]. Later work on Facility Model [7], Manufacturing Model [1, 10, and 11] has underpinned the work presented in this paper.

The Manufacturing Model must represent the manufacturing capability and capacity of a facility. The manufacturing information entities: resources, processes and strategies. The manufacturing resources and processes describe generic capability information. Different companies can use similar types of manufacturing resources and processes. In fact, two companies can have the same type of technology, i.e. manufacturing resources and processes. Nevertheless, the manufacturing facility of each of these companies could perform in a different way because of the company's decisions on how to organise and use those resources and processes. This aspect must be captured to truly represent the manufacturing capability of a company. The manufacturing strategies represent this company specific information which allows a company to specify how the resources and processes are organised and used in order to support the company's manufacturing function (figure 1). The methodology has the following phases:

1. Identification of manufacturing resources and processes.

2. Manufacturing Model configuration: resources and processes.

3. Identification of manufacturing strategies.

4. Establishing relationships between: resources, processes and strategies

5. Manufacturing Model construction and documentation using EXPRESS

6. Manufacturing Model implementation using Object Oriented Database

The IDEF0 process model has already defined resources and processes as mechanism used in product development activities. However there is the need to include relevant information regarding resources (e.g. physical dimensions and restrictions), processes (e.g. capacity, capability, and behaviour) and strategies (e.g. factory location, cost and performance). For example, continuing with the example of bottle design, it requires a mould to produce the bottle and the glass processing machine (e.g. IS machine). The mould has to be designed and manufactured according to bottle specification but historical information of moulds allows designers to design better mould using best practices guidelines. It is important to have information regarding the performance of a mould, machine and process. Then it is possible to predict the behaviour of a mould in a specific machine and process. This information is included in the Manufacturing Model. Strategies are related to 
the selection of the best facility to run a specific mould to product a bottle. This decision has to be based on different factors: localisation (i.e. close to customer), facility performance (i.e. historical performance of family of moulds), and facility cost.

The modelling methodology defined above allowed the authors to have a systematic approach to capture and represent information readily to be documented in EXPRESS and then be programmed in the object-oriented database. Details can be found in Molina and Bell [11].

\subsection{Modelling Knowledge: Integrating Product and Manufacturing Information}

The product and manufacturing information modelled can be used during the product development at different stages where a diversity of data and information can help engineering decision-making. However there is a need to create a higher level of support, i.e. knowledge based engineering. Functions that relate different variables of both models to construct the knowledge model. These functions are different types of relation that can describe: how the thickness of a bottle will affect the glass filling, or thermal behaviour of the mould, or how a radius or angle will created an area of concentration of glass. All these knowledge can be described in three forms:

1. Based on rules. There are two types of rules: Boundary rules and Conditional rules. Boundary Rules, which a specific pre-set range is determined for a particular variable (i.e. the pressure inside a pipe system has to be in between 80 to $120 \mathrm{psi}$ ). Conditional Rules, which are does who modify variables based on input parameters (i.e. the diameter of a drilling tool has to be the diameter of the hole minus $0.005 \mathrm{inch}$ ).

2. Based on Cases: Cases are the description of solutions of specific problem based on set of well-bounded variables. For example, best set-up of a machine based on historical data, forecast performance of a mould and solving production problems of low efficiency.

3. Based on Engineering Models: Knowledge based on mathematical relations that construct formal engineering models is considered within this group. This type of knowledge could be seen as a "black-box" that receives input variables and returns a specific scenario or analysis of a certain group of variables. Commonly knowledge based in models is related with knowledge based on rules, because the results of the first will need further analysis to make a decision. Some examples of this type of knowledge are fluid flow analysis inside a mould, calculating the maximum flow, the critical cross sectional area and the critical pressure location. The corrosion vs. time analysis at the inside walls of a glass 
furnace; by using a mathematical model it is possible to obtain a curve with important critical values.

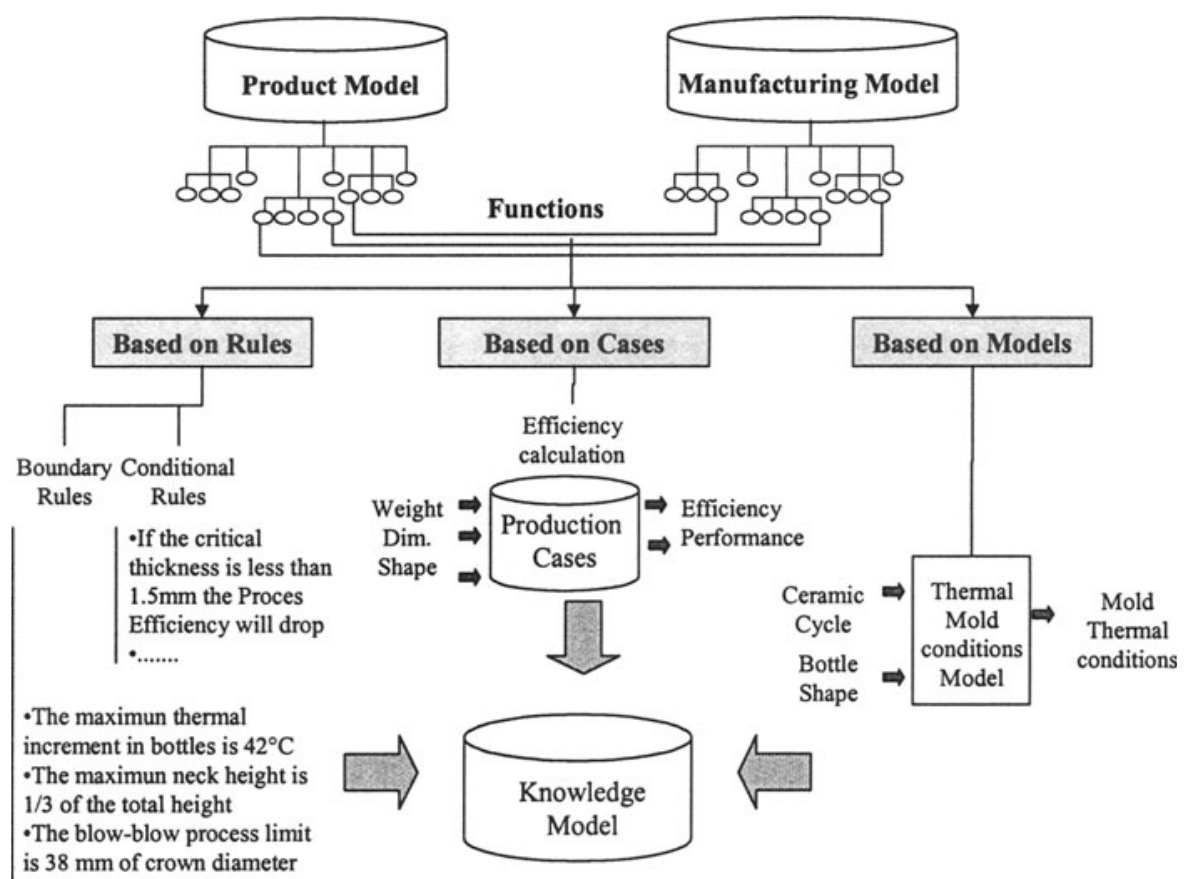

Figure 2. Building a Knowledge Model based on rules, cases and engineering models.

An example in relation to the glass bottle development is presented in figure 2. The rules mentioned are divided in boundary and conditional rules. The first one represents knowledge that could be included in further fuzzy logic analysis. The cases and models shown are simplifications of real analysis tools implemented in a glass company. This Knowledge model is embedded in the Product and Manufacturing Model implementation. 


\section{WEB-BASED INFORMATION TECHNOLOGY FOR VIRTUAL ENTERPRISES}

The Product and Manufacturing Models can be used in product development in Virtual Enterprises. VIRPLAS, which stands for VIRtual industry cluster for PLAStics, was created to explore how the concept of Virtual Enterprises could enhanced the regional development of the plastic industrial sector of Monterrey, Mexico [4]. VIRPLAS has six members with different competencies within the plastic industry. One company is focused on product and mould design, another has capabilities to design and manufacture injection moulds components, two companies are on the business of injection moulding, and one company is specialised in commercialisation of plastic products and machinery. All these companies are Small and Medium Enterprises (SMEs). (www.mexicanindustry.com.mx).

In order to create plastic products, one of the six members (Partner A) will be in charge of the part design; Partner B will be in charge of mould design. Partner A and B will use the Web-based Design for Injection Moulding System (SPEED) to design the product and mould. In order to select the companies which will produce the product, Partner A will use the Web-based Manufacturing Model to select the members of VIRPLAS which have the capabilities to inject the product. Partner C and Partner D will receive the mould from Partner $B$ and will produce the part. As soon as the parts are manufactured they will be sent to the end-customer.

Both Web-based systems are based on the use of Internet and object oriented database technologies. The system was developed with Java and use Object Store OODBMS in order to provide efficient retrieval of the data and management of the complex data model.

The databases reside on a Sun Ultra 5 Server which works as a Web Server. The interfaces to access the SPEED and Manufacturing Model prototype systems were developed with Java applets and can be accessed through any common browser, i.e. Netscape or Explorer.

\subsection{INJECTION MOULDING PRODUCT DEVELOPMENT}

SPEED (Supporting Plastic enginEEring Development) is an information system based on INTERNET that captures the capabilities and characteristics of the injection moulding process to ensure the manufacturability of the plastic product and to define its production resources [2]. Three engineering applications within the SPEED prototype system have been developed. They are: 
1. Design for Mouldability for the plastic product.

2. Support for the mould design and selection of components.

3. Selection of injection moulding machine.

The use of SPEED, is very important for the collaboration of VIRPLAS companies, this application can be customised according the requirement of each one of the companies and has the ability of extend as far as the user needs, see figure 3 for an example of product development (http://speed.mty.itesm.mx).

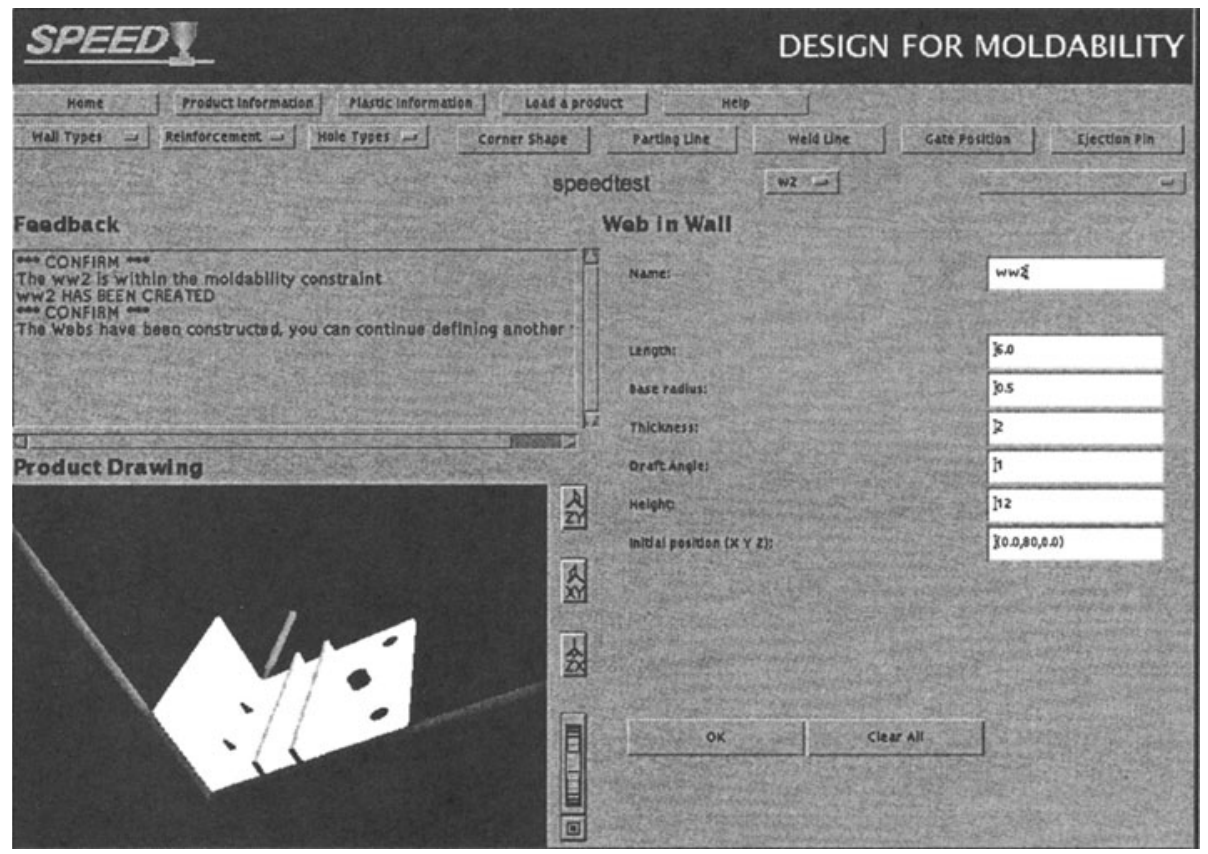

Figure 3. SPEED product development process

\subsection{MANUFACTURING MODEL FOR SUPPLIERS SELECTION IN A VIRTUAL ENTERPRISE}

The Web-based Manufacturing Model was implemented with the idea of supporting selection of suppliers in Virtual Enterprise. The prototype system allows capturing manufacturing information related to resources, processes 
and strategies of a company. The information about a factory can be capture at different levels within the organisation, for example Factory, Shop floor, Cell and Station. This is important because the model also supports the organisation of this information for the companies in the database. Figure 4 shows the interface for data entry in the Manufacturing Model.

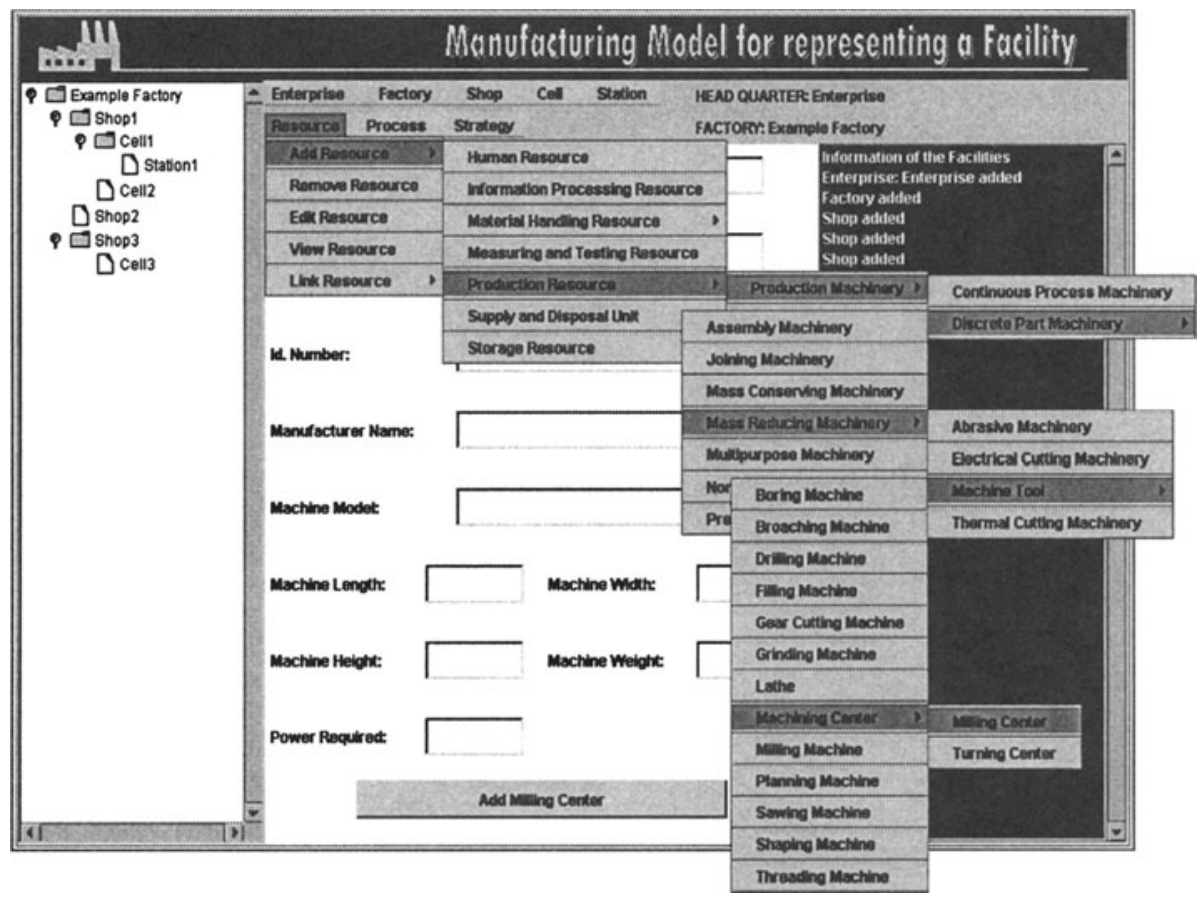

Figure 4. Manufacturing Model data entry interface

Queries can be performed to find machines and processes in the database, also companies that are capable of performing a process o have a specific resource. Sometimes the search for suppliers in a Virtual Enterprise requires to query in specific clusters, for example all companies that can process plastics or are die and mould makers, and so on. Figure 5 shows the query interface that can be accessed in the Virtual Industry Cluster homepage (www.mexican-industry.com.mx ). 


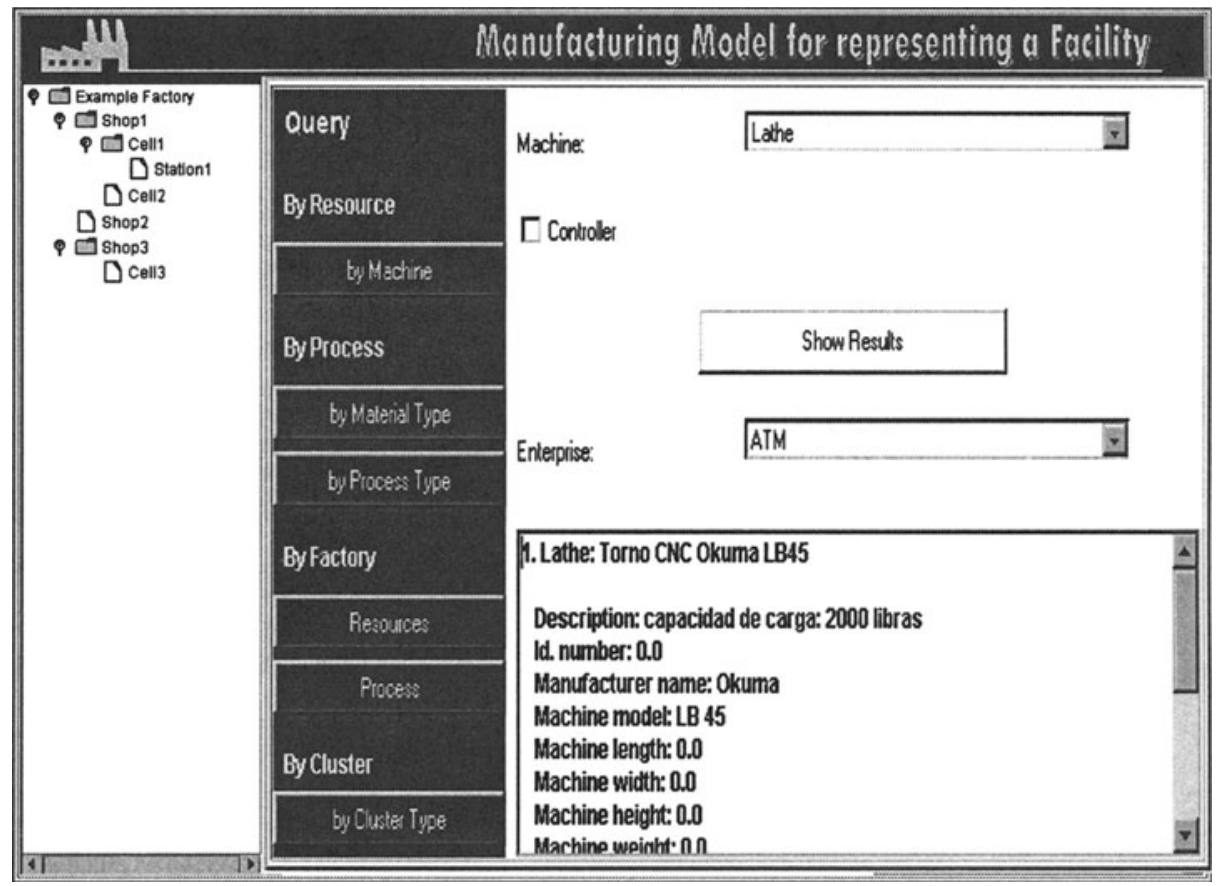

Figure 5. Manufacturing Model query interface

\section{CONCLUSIONS}

In summary this paper describes two methodologies developed to define and create two information models required to support integrated product development i.e. Product and Manufacturing Models. Also the definition of a Knowledge Model which relates both models has been described. These methodologies have been proved to be effective and feasible for the development Web-based prototype systems to support product design in Virtual Enterprises: SPEED and Web-based Manufacturing Model. These prototype systems have been developed using an object-oriented database (Object Store) and Java applets. These applications have demonstrated that Web-based applications are a powerful tool to support global collaboration in product development. 


\section{REFERENCES}

[1] Al-Ashaab A., and Young R.I.M, (1992), "Information Models: An Aid to Concurrency in Injection Moulded Products Design", Presented in the Winter Annual Meeting '92 of ASME. Anaheim, California, Nov. 8-13.

[2] Al-Ashaab A., Rodriguez K., Cárdenas M., Gonzalez J., Molina A., Saeed M. and Abdalla H., (2000), "INTERNET Based Information System to support Global Collaborative Manufacturing", 6th International Conference on Concurrent Enterprising, ICE 2000, France.

[3] Bullinger H.-J., Warshat J., Fischer D., (2000), "Rapid Product Development - an overview", Computers in Industry, 42 (2000), 99-108.

[4] Flores M., Molina A. (2000), "Virtual Industry Clusters: Foundation to create Virtual Enterprises", in Advanced in Networked Enterprises - Virtual Organizations, Balanced Automation and Systems Integration, L.M. Camarinha-Matos, H. Afsarmanesh, HeinzH. Erbe (Eds.), Kluwer Academic Publishers, 2000, pp. 111- 120.

[5] IMPPACT, (1991), Esprit No. 2165, Proceedings of the Workshop, Berlin, 26-27 February 1991.

[6] Krause F-L., Kimura F., Kjellberg T., and Lu S.C.-Y., (1993), "Product Modelling", Keynote papers, Annals of the CIRP, Keynote paper, Vol. 42/2/1993, pp. 695-706.

[7] Molina A., Mezgar I., and Kovacs G., (1992), "Object Knowledge Representation Models for Concurrent Design of FMS", in Human Aspects in Computer Integrated Manufacturing, G.J. Olling, F. Kimura (Editors), Elsevier Science Publishers B.V.(North Holland),IFIP, pp.779-788.

[8] Molina, A., Ellis, T.IA., Young, R.I.M. and Bell, R., (1994), "Methods and Tools for Modelling Manufacturing Information to Support Simultaneous Engineering", Preprints, 2nd IFAC/IFIP/IFORS Workshop Intelligent Manufacturing Systems - IMS'94, (Ed. P. Kopacek), Vienna - Austria - June 13-15, 1994, pp. 87-93.

[9] Molina, A., Al-Ashaab, A.H., Ellis, T.I.A, Young, R.I.M, Bell R., (1995), "A Review of Computer Aided Simultaneous Engineering Systems", Research in Engineering Design, 7: 38-63.

[10] Molina A., Ellis T.I.A, Young R.I.M, Bell R., (1995), "Modelling Manufacturing Capability to Support Concurrent Engineering", Concurrent Engineering: Research and Applications, Volume 3, Number 1, March, pp. 29-42.

[11] Molina A., and Bell R., (1999), "A manufacturing model representation of a flexible manufacturing facility”, Proc Instn Mech Engrs Vol 213 Part B, 1999, pp. 225-246. 